\title{
Social, environmental, and epidemiological aspects of leprosy occurrence in children in a hyperendemic region of Brazil
}

\author{
Fabiane Verônica da Silva ${ }^{a}$, Gutembergue dos Santos Sousa ${ }^{a}$, \\ Pãmela Rodrigues de Souza Silva ${ }^{a}$, Emerson Soares dos Santos ${ }^{b}$, \\ R. B. F. Machadoc ${ }^{c}$, Denise da Costa Boamorte Cortela ${ }^{\mathrm{a}} \&$ \\ Silvana Margarida Benevides Ferreira ${ }^{\mathrm{a}}$ \\ ${ }^{a}$ Postgraduate Program in Nursing, Federal University of Mato Grosso, \\ Brazil \\ ORCID: https://orcid.org/0000-0002-6922-4120 \\ ${ }^{\mathrm{b}}$ Teacher Education and Postgraduate Studies, Federal University of Mato \\ Grosso, Brazil \\ ${ }^{\mathrm{c}}$ Environmental Lawyer, University of Coimbra - UC, Portugal
}

Submitted 5 June 2021; Accepted 3 September 2021

\begin{abstract}
Summary
Introduction This is a case-control study aiming to analyze the predictive factors for the occurrence of leprosy in contacts under 15 years of age, considering aspects related to the socio-environmental and epidemiological conditions in a hyperendemic municipality.

Methods Cases $(n=30)$ consisted of children with leprosy who were household contacts of adults notified with leprosy between 2016 and 2018. The controls $(n=128)$ comprised neighborhood contacts, without symptoms of leprosy, living within a radius of less than $100 \mathrm{~m}$ of the households with cases. Demographic, social, environmental, and epidemiological variables were analyzed. The software SPSS, version 20, was used. Odds Ratio and statistical significance level of $p \leq 0.05$ were considered for association analysis. In the logistic regression analysis, the variables with results $\leq 20 \%$ were selected.

Results After adjustments, the predictive variables for the occurrence of leprosy were age between 8 and 14 years (OR adjust $=4.5 ; 95 \%$ CI: $1.70 ; 12.18)$ and a family history of leprosy (OR adjust $=5.2 ; 95 \%$ CI: $1.95 ; 14.13$ ).

Conclusions The predictive factors studied may favor the occurrence of leprosy in those most vulnerable to this disease in the child population; strategies such as the use of immune chemoprophylaxis are recommended, especially in hyperendemic regions, such as the state of Mato Grosso.
\end{abstract}

Keywords: Leprosy, risk factor, contact, child population

Correspondence to: Fabiane Verônica da Silva (e-mail: faby.vero@hotmail.com)

Please note that the authors' affiliations were corrected on December 20, 2021.

(C) The author(s). This article is Open Access under CC BY 4.0 


\section{Introduction}

Leprosy is characterized as an infectious, transmissible disease of chronic nature, whose etiological agent is Mycobacterium leprae. Despite advances in leprosy control in endemic countries, it still persists as a public health problem in Brazil. ${ }^{1,2}$

The World Health Organization (WHO) registered 202,185 new cases of the disease worldwide in 2019, of which 7.4\% occurred in children under 15 years of age. Between 2010 and 2019, Brazil registered 20,684 new cases of leprosy in this age group and, in 2019, of the 1545 new cases reported, the detection rate was 3.44 per 100,000 children. ${ }^{1,2}$ Also worthy of notice is the relevance of cases diagnosed with grade 2 physical disability, in the same year, of 11.16 cases per 1 million inhabitants (1108 new cases). ${ }^{1}$ In this scenario, Brazil remains with a hyperendemic profile, ranking second among the countries with the highest number of new cases of the disease in the world. ${ }^{1,2}$

In 2019, the state of Mato Grosso (MT), located in the Center-West region of Brazil, had a total detection rate of 129.38/100,000 inhabitants from 4424 new cases of leprosy; of these new cases reported, in the same period, 179 records were in children under 15 years of age (rate of 22.76/100,000 children). ${ }^{1}$ In that same year, among the 141 municipalities with registration of the disease in the State, its capital Cuiabá reported 313 new cases, which represented a detection rate of 50.45/100,000 inhabitants, placing it as a priority municipality for the development of strategic actions for the disease. .,3 $^{\text {Cop }}$

Coping with leprosy is a challenge not only for the health system, since it also suggests social vulnerability, characterized by poor housing conditions, low levels of education, low income, and inefficient sanitation services. The deficits in the health services are also exposedespecially in developing countries. ${ }^{4}$

It is estimated that the chance of detecting a patient with undiagnosed leprosy is ten times higher in the household contacts of patients with the disease than in the general population, and this probability is three to five times higher among neighborhood and/or social contacts. ${ }^{3,5}$ Regular surveillance of contacts of cases of leprosy is a crucial strategy to assess exposure to the bacillus among those people most likely to become ill and, consequently, to improve plans for early diagnosis and timely treatment of all cases identified. . $^{6}$

M. leprae is also present in the environment, and several factors may be associated with higher rates of detection of leprosy; for example, meteorological factors, such as temperature, environmental humidity, rugged relief with medium-sized shrubs, predominant vegetation of the Amazon forest, with mild temperatures, in areas with migration resulting from mining activities, peripheral areas of cities, and agricultural borders. ${ }^{7,8}$

Owing to the possible factors that contribute to the hyperendemicity of this disease, this study aimed to analyze the predictive factors for the occurrence of leprosy among household contacts, under the age of 15 , regarding aspects relative to the socio-environmental and epidemiological conditions in the capital of the state of Mato Grosso, Center-West region of Brazil.

\section{Methods}

This is a case-control study conducted in the city of Cuiabá, capital of the state of Mato Grosso. The study included 158 children under 15 years.

The study was developed in the state of Mato Grosso, in the municipality of Cuiabá, comprising urban and rural areas that had cases of leprosy in children and adolescents that were household contacts of cases diagnosed with the disease. 
The municipality of Cuiabá extends over $3,362.8 \mathrm{~km}^{2}$, has demographic density of 163.88 inhabitants $/ \mathrm{km}^{2}$, with a Human Development Index (HDI) of 0.785 and a population of 618,124 inhabitants, $175,573(28.40 \%)$ of whom are children under 15 years of age. ${ }^{9}$

The following criteria defined Cases: all newly diagnosed cases of leprosy in children under the age of 15 , who were living in households with adults confirmed with leprosy and registered in the Notifiable Diseases Information System (SINAN) between 2016 and 2018. Of this selection, 41 children whose diagnosis was made according to the evaluation by physicians from health centers for the treatment of the disease were eligible for the study. Eleven contacts with a diagnosis of leprosy were excluded (not found, diagnostic error, transfer to other municipalities, and duplicates). Thus a total of 30 children under 15 years of age with leprosy were analyzed.

Controls consisted of all children under the age of 15, without leprosy, who lived within a radius of $100 \mathrm{~m}$ from one of the Cases $(n=137)$. Of these, 9 children were excluded for diagnostic suspicion of leprosy according to the evaluation of all controls by physicians from health centers for the treatment of the disease. Thus in total there were 128 children in the control group (ratio of 1:4 controls).

Variables selected in the study: demographic, socioeconomic, socio-environmental, epidemiological/clinical, and the presence of a vaccine scar from BCG (Bacillus CalmetteGuérin). Demographic (race/color) and socioeconomic (class A, B, C and D) variables were estimated according to the Brazilian Institute of Geography and Statistics. ${ }^{9}$

The clinical variables were those related to the diagnosis of leprosy: clinical form, operational classification, and level of physical disability.

The socio-environmental variables were: construction material of the house, accessibility to the place of residence (with or without obstacles), hygiene in the surroundings; garbage collection, number of houses on the piece of land, asphalt pavement, household coating/plastering, household finishing/painting, presence of afforestation on the site (tree; shrub; mixed or without afforestation), and amount of afforestation on site.

For data collection, a semi-structured questionnaire was applied to the research participants by a team consisting of five nurses specialized in the disease, and information was also collected from the medical records between August and December 2018.

The interviews were conducted in the informants' households and/or at health centers. The questions were answered by children under 15 years and/or by their legal guardians.

Data collection only started after the research project had been presented and, subsequently, a Free and Informed Consent Form had been signed by parents/guardians, and the Term of Assent had been applied to minors according to age group ( 5 to 7 years; 8 to 10 years; 11 to 14 years).

The households were identified through geographic coordinates of the addresses with the aid of Garmin 76Cx GPS/MAP version 5.00.

The software SPSS (IBM SPSS Statistics for Windows, version 20.0, NY, USA) was used to manage and analyze the data. Data consistency was evaluated through the VALIDATE App (Microsoft $^{\circledR}$, Power Apps, Validate, WA, USA). For the exploratory analysis of quantitative data, such as age, mean and standard deviation were considered. Absolute and relative frequency measures were considered for independent categorical variables. The odds ratio (OR) was used to determine the association between the predictor variables and the outcome, with a $95 \%$ confidence interval. The variables with $p<0.20$ were inserted using the stepwise method in the logistic regression model, and those with statistical significance, with a $p \leq 0.05$, were maintained in the final model. 
Table 1. Distribution of leprosy in contacts (cases and controls) under 15 years of age, Crude Odds Ratio (OR), according to demographic and social variables by region of residence

\begin{tabular}{|c|c|c|c|c|c|c|c|}
\hline \multirow[t]{3}{*}{ Characteristics } & \multicolumn{4}{|c|}{ Leprosy contacts } & \multirow[t]{3}{*}{ OR crude } & \multirow[t]{3}{*}{ CI $(95 \%)$} & \multirow[t]{3}{*}{$p$-value } \\
\hline & \multicolumn{2}{|c|}{ Cases } & \multicolumn{2}{|c|}{ Controls } & & & \\
\hline & $\mathrm{N}$ & $\%$ & $\mathrm{~N}$ & $\%$ & & & \\
\hline \multicolumn{8}{|l|}{ Demographic } \\
\hline \multicolumn{8}{|l|}{ Age } \\
\hline $1-7$ years old & 7 & 23.3 & 69 & 53.9 & 1 & & \\
\hline $8-14$ years old & 23 & 76.7 & 59 & 46.1 & 3.84 & $1.53-9.59$ & 0.002 \\
\hline \multicolumn{8}{|l|}{ Sex } \\
\hline Female & 17 & 56.7 & 58 & 45.3 & 1 & & \\
\hline Male & 13 & 43.3 & 70 & 54.7 & 0.63 & $0.28-1.41$ & 0.262 \\
\hline \multicolumn{8}{|l|}{ Race/skin color ${ }^{1}$} \\
\hline Not brown & 10 & 33.3 & 43 & 34.1 & 1 & & \\
\hline Brown & 20 & 66.7 & 83 & 65.9 & 1.04 & $0.44-2.41$ & 0.934 \\
\hline \multicolumn{8}{|l|}{ Region of residence } \\
\hline West & 4 & 13.3 & 22 & 17.2 & 1 & & \\
\hline North & 19 & 63.3 & 79 & 61.7 & 1.32 & $0.40-4.29$ & 0.441 \\
\hline East & 1 & 3.3 & 4 & 3.1 & 1.37 & $0.12-15.72$ & 0.612 \\
\hline South & 5 & 16.7 & 19 & 14.8 & 1.44 & $0.33-6.17$ & 0.446 \\
\hline Guia municipality & 1 & 3.3 & 4 & 3.1 & 1.37 & $0.12-15.72$ & 0.612 \\
\hline \multicolumn{8}{|l|}{ Social } \\
\hline \multicolumn{8}{|l|}{ Economic class ${ }^{2}$} \\
\hline $\mathrm{A} / \mathrm{B}$ & 3 & 10.3 & 17 & 13.3 & 1 & & \\
\hline $\mathrm{C}, \mathrm{D}, \mathrm{E}$ & 26 & 89.7 & 111 & 86.7 & 1.32 & $0.36-4.86$ & 0.472 \\
\hline \multicolumn{8}{|l|}{ Type of housing 3} \\
\hline Own & 25 & 86.2 & 106 & 82.8 & 1 & & \\
\hline Rented/Ceded & 4 & 13.8 & 22 & 17.2 & 0.77 & $0.24-2.43$ & 0.449 \\
\hline \multicolumn{8}{|c|}{ Number of people in the household 4} \\
\hline 1 to 4 people & 14 & 48.3 & 56 & 43.8 & 1 & & \\
\hline 5 or more & 15 & 51.7 & 72 & 56.2 & 0.83 & $0.37-1.86$ & 0.657 \\
\hline \multicolumn{8}{|c|}{ Number of houses on the lot } \\
\hline 1 house & 25 & 83.3 & 113 & 88.3 & 1 & & \\
\hline 2 or more houses & 5 & 16.7 & 15 & 11.7 & 1.50 & $0.50-4.53$ & 0.463 \\
\hline \multicolumn{8}{|l|}{ Basic Sanitation } \\
\hline Shared sewer & 3 & 10.0 & 24 & 18.7 & 1 & & \\
\hline Pit latrine & 27 & 90.0 & 104 & 81.3 & 2.07 & $0.58-7.41$ & 0.417 \\
\hline \multicolumn{8}{|l|}{ Home hygiene } \\
\hline Present & 5 & 16.7 & 34 & 26.6 & 1 & & \\
\hline Absent & 25 & 83.3 & 94 & 73.4 & 1.80 & $0.64-5.10$ & 0.257 \\
\hline \multicolumn{8}{|c|}{ Grouped home accessibility } \\
\hline Without barriers & 18 & 60.0 & 64 & 50.0 & 1 & & \\
\hline With barriers & 12 & 40.0 & 64 & 50.0 & 0.66 & $0.29-1.49$ & 0.323 \\
\hline
\end{tabular}

Note: Ignored: demographic: ${ }^{1}$ controls $(n=2)$; Social: ${ }^{2-4}$ case $(n=1)$.

The study was approved by the Human Research Ethics Committee under Protocol No. 443.830 .

\section{Results}

Of the 158 cases and controls, $19 \%$ were cases and $81 \%$ controls, with a mean age of 7.72 years (minimum 1 year, maximum 14 years; $S D= \pm 4.13$ ). Among the cases, $53.3 \%$ were multibacillary $(n=16 / 30)$ and $50 \%(n=15 / 30)$ had the borderline clinical form. It was 
Table 2. Distribution of leprosy in contacts (cases and controls) under 15 years, Crude Odds Ratio, according to environmental and epidemiological variables

\begin{tabular}{|c|c|c|c|c|c|c|c|}
\hline \multirow[t]{3}{*}{ Characteristics } & \multicolumn{4}{|c|}{ Leprosy contacts } & \multirow[t]{3}{*}{ OR crude } & \multirow[t]{3}{*}{ CI $(95 \%)$} & \multirow[t]{3}{*}{$p$-value } \\
\hline & \multicolumn{2}{|c|}{ Cases } & \multicolumn{2}{|c|}{ Controls } & & & \\
\hline & $\overline{\mathrm{N}}$ & $\%$ & $\mathrm{~N}$ & $\%$ & & & \\
\hline \multicolumn{8}{|l|}{ Environmental } \\
\hline \multicolumn{8}{|l|}{ Asphalt paving ${ }^{1}$} \\
\hline Present & 18 & 60.0 & 63 & 52.9 & 1 & & \\
\hline Absent & 12 & 40.0 & 56 & 47.1 & 0.75 & $0.33-1.69$ & 0.487 \\
\hline \multicolumn{8}{|c|}{ Home coating/plaster } \\
\hline Present & 23 & 76.7 & 107 & 83.6 & 1 & & \\
\hline Absent & 7 & 23.3 & 21 & 16.4 & 1.55 & $0.58-4.07$ & 0.371 \\
\hline \multicolumn{8}{|c|}{ Home finishing/painting } \\
\hline Present & 20 & 66.7 & 73 & 57.0 & 1 & & \\
\hline Absent & 10 & 33.3 & 55 & 43.0 & 0.66 & $0.28-1.53$ & 0.334 \\
\hline \multicolumn{8}{|l|}{ Residential coverage } \\
\hline Mud & 14 & 46.7 & 62 & 48.4 & 1 & & \\
\hline Asbestos/Mixed & 16 & 53.3 & 66 & 51.6 & 1.07 & $0.48-2.38$ & 0.861 \\
\hline \multicolumn{8}{|c|}{ Surrounding vegetation } \\
\hline Absent & 3 & 10.0 & 34 & 26.6 & 1 & & \\
\hline Present & 27 & 90.0 & 94 & 73.4 & 3.25 & $0.92-11.42$ & 0.054 \\
\hline \multicolumn{8}{|l|}{ Epidemiological } \\
\hline \multicolumn{8}{|c|}{ Family history of leprosy } \\
\hline $\mathrm{No}$ & 7 & 23.3 & 83 & 64.8 & 1 & & \\
\hline Yes & 23 & 76.7 & 45 & 35.2 & 6.06 & $2.41-15.21$ & $<0.001$ \\
\hline \multicolumn{8}{|l|}{ Typical BCG scar ${ }^{2}$} \\
\hline With scar & 25 & 86.2 & 120 & 96.0 & 1 & & \\
\hline No scar & 4 & 13.8 & 5 & 4.0 & 3.84 & $0.96-15.32$ & 0.065 \\
\hline
\end{tabular}

Note: Ignored: environmental: ${ }^{1}$ controls $(n=9)$; epidemiological: ${ }^{2}$ case $(n=1)$, controls $(n=3)$.

observed that $40 \%$ of the cases $(n=12 / 30)$ were not evaluated regarding the degree of physical disability in leprosy and $63.3 \%(n=19)$ of the children lived in the northern region of the city (Table 1).

The bivariate analysis showed that the factors associated with the occurrence of leprosy related to demographic and epidemiological aspects were age categorized into 8 to 14 years (OR: 3.84 95\% CI: 1.53-9.59) and family history of leprosy (OR: 6.06 95\% CI: 2.41-15.21). The other variables investigated did not show statistically significant differences (Tables 1 and 2).

In the adjusted analysis, a 4.54-fold greater chance of occurrence of leprosy was observed among children under 15 years old, aged between 8 and 14 years old, when compared to those under 7 years old (adjusted OR: 4.54; 95\% CI: 1.70-12.18), and greater than 5.25 times among those with a history of leprosy in the family compared to the absence of this condition (adjusted OR: 5.25; 95\% CI: 1.95-14.13) (Table 3).

\section{Discussion}

The main findings of this study indicate a greater chance of occurrence of leprosy among children under 15 years old, aged between 8 and 14 years old, and when there was a family history of the disease. These results enhance the evidence of the relationship of early exposure of children and the occurrence of leprosy in unfavorable socio-epidemiological conditions, 
Table 3. Logistic regression of predictive factors to the occurrence of leprosy (cases vs. controls) under 15 years of age

\begin{tabular}{|c|c|c|c|c|}
\hline Characteristics & OR crude & OR adjusted & CI $(95 \%)$ & $p$-value \\
\hline \multicolumn{5}{|l|}{$\overline{\text { Age }^{1}}$} \\
\hline $1-7$ years old & 1.00 & 1.00 & & \\
\hline $8-14$ years old & 3.84 & 4.54 & $1.70-12.2$ & 0.003 \\
\hline \multicolumn{5}{|c|}{ Surrounding vegetation ${ }^{2}$} \\
\hline Absent & 1.00 & 1.00 & & \\
\hline Present & 3.25 & 2.74 & $0.60-12.6$ & 0.195 \\
\hline \multicolumn{5}{|c|}{ Family history of leprosy ${ }^{3}$} \\
\hline $\mathrm{No}$ & 1.00 & 1.00 & & \\
\hline Yes & 6.06 & 5.25 & $1.95-14.1$ & 0.001 \\
\hline \multicolumn{5}{|l|}{ Typical BCG ${ }^{4}$ scar } \\
\hline With scar & 1.00 & 1.00 & & \\
\hline No scar & 3.84 & 4.62 & $0.84-25.3$ & 0.077 \\
\hline
\end{tabular}

Note: ${ }^{1}$ Adjusted by presence of surrounding vegetation, typical BCG vaccine scar and family history of leprosy; ${ }^{2}$ Adjusted for age, typical BCG vaccine scar and family history of leprosy; ${ }^{3}$ Adjusted for age, presence of surrounding vegetation and typical BCG vaccine scar; ${ }^{4}$ Adjusted for age, presence of surrounding vegetation and family history of leprosy.

which can explain the permanence of endemicity in the Center-West region of Brazil and, consequently, the perpetuation of the disease as a public health problem. . $^{1,3,10}$

In areas considered endemic, the presence of infection in children indicates intense circulation and dissemination of the bacillus. Therefore, the identification of groups at higher risk of developing leprosy becomes essential, especially in the child population considered more vulnerable to illnesses. Early diagnosis is one of the important strategies in a susceptible population, especially amongst the contacts of leprosy patients, who should be the priority in disease control programs aiming at stopping transmission and reducing physical and social disabilities. In this study, $40 \%$ of cases were not evaluated for the degree of physical disability in leprosy. One of the purposes of the 2016-2020 global leprosy strategy is to focus on children, and targeting the reduction of physical disabilities, which can minimize the stigmatizing conditions of the disease. ${ }^{11}$

The findings showed the highest proportion of leprosy cases in the Northern region of the municipality, considered the most socioeconomically vulnerable, with the highest population density in the municipality studied. ${ }^{12,13}$ The concentration of cases is commonly associated with migratory movement and living conditions in cities, which can encourage foci of transmission. ${ }^{14}$

Social and environmental conditions did not indicate an association with the occurrence of leprosy. However, future studies are required for an in-depth analysis of this issue. The occurrence of cases may be related to environmental conditions that encourage transmission. ${ }^{8,15}$ Studies seeking to investigate new scientific evidence of links between environmental variables and the occurrence of leprosy, such as the presence of vegetation and its characteristics, or of deforestation, will be relevant to understanding the dynamics of the disease in endemic areas.

A higher chance of disease occurrence was evidenced among cases with a leprosy history in the family. Home contact with multibacillary patients is known to present a higher chance of illness, especially in a hyperendemic region, confirming the historical trend of this disease presence in the state of Mato Grosso. ${ }^{3,16,17}$ We emphasize that the planning of actions with the objective of monitoring the contacts and systematizing care should be prioritized, aiming at the 
early diagnosis and timely treatment of all cases. In children under 15 years who are suspected of having leprosy, the complementary protocol for diagnostic investigation of leprosy cases shall be applied in accordance with the recommendations of the Brazilian Ministry of Health. ${ }^{18}$

The sample size in this study may have been too low to show an effect of BCG vaccine. Studies show that neonatal BCG vaccine can provide about $60 \%$ protection against the transmission of $M$. leprae to household contacts, but when a contact already vaccinated with BCG receives further immune prophylaxis, the protective effect increases about $80 \% .{ }^{19-21}$

On the other hand, our results support the need for chemoprophylaxis with single dose of rifampicin for contacts, since evidence indicates the reduction of the disease incidence in contacts who received the intervention. ${ }^{19,22,23}$

Limitations of this study are those relative to sample size, indicated by the amplitude of the confidence intervals. However, in an attempt to increase the robustness of the analyses, all cases of leprosy found in the study population and their controls were selected during the study period. However, the findings of the study can be useful in supporting health interventions to control the disease in this specific group.

It is concluded that factors associated with leprosy indicate greater vulnerability in children aged between 8 and 14 years, as well as in those with a family history of the disease. Interventions for contacts with immuno-chemoprophylactic strategies and intensification of disease elimination actions are essential. The systematization of care should be expanded to the neighborhood and social contacts, especially in hyperendemic regions, such as the state of Mato Grosso.

\section{Conflicts of interest}

The authors declare no conflicts of interest.

\section{Financial support}

National Council of Science and Technology development (CNPQ), Process number: 435239/2018-0, Call: UNIVERSAL 2018.

\section{Author contribution}

Miss Fabiane Verônica Silva, Mr. Guttembergue Santos Sousa were involved in study conceptualization and design, obtaining permission for conducting the study, conducting interviews, data collection, data analysis and interpretation, and writing the manuscript. Dr. Pamela Rodrigues de Souza Silva, Emerson Souza Santos, Rafaela Benevides Ferreira Machado were involved in study conceptualization and design, monitoring the study and commenting on the manuscript. Dr. Denise da Costa Boamorte Cortela and Silvana Margarida Benevides were involved in data analysis and interpretation, drafting and finalizing the manuscript for submission.

\section{References}

1 Brasil; Ministério da Saúde. Boletim Epidemiológico de Hanseníase. Departamento de Doenças de Condições Crônicas e Infecções Sexualmente Transmissíveis, da Secretaria de Vigilância em Saúde, do Ministério da Saúde (DCCI/ SVS/MS), (2021).

2 World Health Organization. Global leprosy update, 2018: moving towards a leprosy-free world. Wkly Epidemiol Rec, 2019; 94: 389-412. 
3 Freitas BHBMd, Xavier DR, Cortela DdCB, Ferreira SMB. Hanseníase em menores de quinze anos em municípios prioritários, Mato Grosso, Brasil. Rev Bras Epidemiol, 2018; 21: e180016. https://doi.org/10.159 0/1980-549720180016.

4 Fernandes MVC. Associação entre os padrões espaciais da incidência de hanseníase em menores de 15 anos e a condição de vida em Manaus, Am: Universidade Federal do Amazonas - Universidade do Estado do Pará; 2017.

5 Moet FJ, Meima A, Oskam L, Richardus JH. Risk factors for the development of clinical leprosy among contacts, and their relevance for targeted interventions. Lepr Rev, 2004; 75(4): 310-326.

6 World Health Organization. Global leprosy update, 2017: reducing the disease burden due to leprosy. Wkly Epidemiol Rec, 2018; 93: 445-456.

7 Santos ADd, Santos MB, Barreto AS, Carvalho DdS, Alves JAB, Araújo KCGMd. Análise espacial e características epidemiológicas dos casos de hanseníase em área endêmica. Rev enferm UFPE on line, 2016; 10: 4188-4197.

8 Valois E, Campos FMC, Ignotti E. Prevalence of Mycobacterium leprae in the environment: a review. Afr $J$ Microbiol Res, 2015; 9: 2103-2110.

9 Instituto Brasileiro de Geografia e Estatistica (IBGE). https://cidades.ibge.gov.br/.

10 Rodrigues TS, Gomes LC, Cortela DC, Silva EA, Silva CA, Ferreira SM. Factors associated with leprosy in children contacts of notified adults in an endemic region of Midwest Brazil. J Pediatr, 2020; 96: 593-599.

11 Smith CS, Noordeen SK, Richardus JH, Sansarricq H, Cole ST, Soares RC et al. A strategy to halt leprosy transmission. Lancet Infect Dis, 2014; 14: 96-98.

12 Palit A, Kar HK. Prevention of transmission of leprosy: The current scenario. Indian J Dermatol Venereol Leprol, 2020; 86: 115-123.

13 de Oliveira AS, Nogueira MCdJA, Sanches L, De Musis CR. Microclima urbano - praças públicas em Cuiabá/MT/Brasil. Caminhos Geogr, 2012; 13.

14 Cortela DdCB, Ferreira SMB, Virmond MCL, Mieras L, Steinmann P, Ignotti E et al. Aceitabilidade da quimioprofilaxia em área endêmica para a hanseníase: projeto PEP-Hans Brasil. Cad Saúde Pública, 2020; 36: e00068719. https://doi.org/10.1590/0102-311X00068719

15 Negrão GN, Vieira IR, Katayama EMY, Borecki MT. Variáveis epidemiológicas intervenientes na ocorrência da hanseníase no Município de Guarapuava, PR. Geografia (Londrina), 2016; 25(2): 110-129.

16 Belda Junior W, Di Chiacchio N, Criado P. Tratado de dermatologia. São Paulo: Atheneu. 2014.

17 Pinto Neto JM, Carvalho HTd, Cunha LESd, Cassenote AJF, Lozano AW, Martins APdS. Análise do controle dos contatos intradomiciliares de pessoas atingidas pela hanseníase no Brasil e no Estado de São Paulo de 1991 a 2012. Hansen int, 2013; 38: 68-78.

18 Brasil. Ministério da Saúde. Guia prático sobre a hanseníase [recurso eletrônico]. Departamento de Vigilância das Doenças Transmissíveis. Secretaria de Vigilância em Saúde. Ministério da Saúde, 2017.

19 World Health Organization. Global Leprosy Strategy 2016-2020: Accelerating Towards a Leprosy-free World. New Delhi: Regional Office for South-East Asia, 2016.

20 Ferreira SMB, Yonekura T, Ignotti E, de Oliveira LB, Takahashi J, Soares CB. Effectiveness of rifampicin chemoprophylaxis in preventing leprosy in patient contacts: a systematic review of quantitative and qualitative evidence. JBI Database Syst Rev Implement Rep, 2017; 15(10): 2555-2584.

21 Richardus R, Alam K, Kundu K, Roy JC, Zafar T, Chowdhury AS et al. Effectiveness of single-dose rifampicin after BCG vaccination to prevent leprosy in close contacts of patients with newly diagnosed leprosy: A cluster randomized controlled trial. Int J Infect Dis, 2019; 88: 65-72.

22 Lockwood DN, De Barros B, Walker SL. Single-dose rifampicin and BCG to prevent leprosy. Int J Infect Dis, 2020; 92: 269-270.

23 Mendonça MA, de Andrade YNL, Rolim ILcTP, de Aquino DMC, da Silva Soeiro VM, dos Santos LH. Perfil epidemiológico dos contatos intradomiciliares de casos de hanseníase em capital hiperendêmica no Brasil. Rev Pesqui Cuid Fundam, 2019; 11(4): 873-879. 